
\title{
Research S Surare \\ Potential benefits and pitfalls of skin-to-skin contact transport from birth room to neonatal unit
}

Nolwenn Clénet ( $\square$ n.clenet@chu-tours.fr )

CHRU de Tours

Laure Carneiro

CHRU de Tours

Carole Jeanneaud

CHRU de Tours

Geraldine Favrais

CHRU de Tours https://orcid.org/0000-0002-0301-2053

\section{Research Article}

Keywords: Healthcare Quality Access and Evaluation, Newborn, Infant, Intensive Care, Preterm Infants, Postnatal Care, Kangaroo-mother Care, Hypothermia, Breastfeeding

Posted Date: March 15th, 2021

DOI: https://doi.org/10.21203/rs.3.rs-324905/v1

License: (9) This work is licensed under a Creative Commons Attribution 4.0 International License. Read Full License 
Potential benefits and pitfalls of skin-to-skin contact transport from birth room to neonatal unit

Nolwenn Clenet, $\mathrm{RN}^{1}$, Laure Carneiro, $\mathrm{MD}^{1}$, Carole Jeanneaud, $\mathrm{RN}^{2}$, Geraldine Favrais, $\mathrm{MD}$, $\mathrm{PhD}^{1,3}$

1 Neonatology Unit, CHRU de Tours, Tours, France

2 Clinical research support team, CHRU de Tours, Tours, France

3 UMR 1253, iBrain, Université de Tours, INSERM, Tours, France

Running Title: Safety and benefit of skin-to-skin transport

\section{Corresponding author:}

Nolwenn Clenet,

Service de Néonatologie-Hôpital Bretonneau, CHRU de Tours,

2 Boulevard Tonnellé,

37044 Tours Cedex 9, France

Phone: +33247474749,

Fax: +33247478728,

Email: $\underline{\text { n.clenet@ chu-tours.fr }}$ 
Financial Disclosure Statement: This study did not receive specific funding.

Completing Interests Statement: The authors have no conflicts of interest to disclose.

Ethical Approval: Written legal consent from guardians for the use of their child's data was obtained. The local ethics committee (2019-082) and local data protection authority (2019054) approved the protocol.

Clinical Trial Registration: Not Applicable

\section{Preprint Disclosure}

This article was first posted on Research Square at the following address: https://www.researchsquare.com/article/rs-324905/private/draft. The authors confirm that if their article is published in ANC, they will notify the relevant parties accordingly so that the preprint version can be linked to the published record.

\section{Acronyms and Abbreviations}

- $\mathrm{FiO} 2$ - Fraction of Inspired Oxygen

- NICU - Neonatal Intensive Care Unit

- $\quad$ SSC - Skin-to-Skin Contact 


\section{Summary of Recommendations for Practice and Research}

\section{What we know:}

- Repeated skin-to-skin contact between preterm infants and their parents during the neonatal period improves maternal bonding, parent-child interactions and long-term infant neurodevelopmental outcomes

- Early skin-to-skin contact between healthy term infants and their mothers in the delivery room promotes thermal stability and breastfeeding

- Interhospital transport of stable newborn infants through skin-to-skin contact is safe and secure for infants, as well as stressless for parents

- Transfer of infants requiring intensive care from the birth room to the neonatal unit through skin-to-skin contact is an emerging practice

\section{What needs to be studied:}

- Evolution of the axillary temperature of newborn infants during skin-to-skin transfer compared to transfer in incubators from birth rooms to neonatal intensive care units

- Cardiorespiratory function of newborn infants during skin-to-skin transfer in comparison with transfer in incubators and impact of transfer mode on first glycemia in the neonatal unit

- Short- and long-term effects of the transfer mode on skin-to-skin contact in the neonatal unit and on breastfeeding

\section{What we can do today:}

- Be confident in skin-to-skin transfer for late preterm and term infants requiring noninvasive ventilatory support without oxygen dependence

- Pay attention to the potential heat loss during the skin-to-skin transfer 
- Implementation of the skin-to-skin transfer mode may improve the skin-to-skin contact quality in the neonatal unit and may thereafter promote breastfeeding 


\section{ABSTRACT}

Background: Early and repeated skin-to-skin contact (SSC) between infants and their parents during neonatal hospitalization has positive effects on maternal bonding, breastfeeding, parent-child interactions and preterm infant neurodevelopmental outcomes.

Purpose: Transfers through SSC of newborn infants requiring intensive care over 300 meters between the birth room and neonatal unit have been implemented since 2018. The safety of SSC transfer with the infant's father was questioned when compared to the more common transfer method in incubators. Methods: Singletons born from May to December 2019 at our three-level maternity ward that required intensive neonatal care were eligible. The infants' axillary temperature, heart rate, and oxygen need were reported at four timepoints during transfer in an incubator or through SSC and at 30 minutes after arrival in the neonatal unit. Infant characteristics, blood gas, glycemia, time-lapse between birth and first SSC in the unit and feeding modes were also reported. Results: Median gestational age was higher in the SSC group (incubator ( $\mathrm{n}=54)$ : 32 weeks vs SSC ( $=57)$ : 36 weeks, $\mathrm{p}=.003)$. All infants requiring mechanical ventilation were transported in an incubator. A decrease in temperature was observed during incubator installation in the SSC group (incubator: $0^{\circ} \mathrm{C}$ vs SSC: $-0.2^{\circ} \mathrm{C}, \mathrm{p}<$ .001 ), but the first SSC in the unit was earlier in this group (incubator: $22 \mathrm{~h}$ vs SSC: $11 \mathrm{~h}, \mathrm{p}=$ .001 and $\mathrm{p}=.008$ after adjustment for gestational age). Implications for practice: Although thermal stability was compromised, encouraging results regarding the first SSC in the unit promote the continuation of SSC transfers.

Key words: Healthcare Quality Access and Evaluation, Newborn, Infant, Intensive Care, Preterm Infants, Postnatal Care, Kangaroo-mother Care, Hypothermia, Breastfeeding. 


\section{INTRODUCTION}

Daily care of infants hospitalized during their neonatal period increasingly involves their parents. Regarding very preterm infants, regular skin-to-skin contact (SSC) during the neonatal intensive care unit (NICU) stay has had positive effects on maternal bonding, parentchild interactions and infant neurodevelopmental outcomes ${ }^{1,2}$. Physiologic parameters of preterm infants were recorded during the SSC course as soon as the first week of life. SSC did not alter cardiorespiratory parameters or cerebral oxygenation of infants even if they required mechanical or noninvasive ventilation support ${ }^{3,4}$. Thermal stability was preserved despite a loss of heat observed during the transfer of the infant from the incubator to the parent and vice versa ${ }^{5,6}$. This transient decrease in body temperature did not have physiological or metabolic consequences ${ }^{6}$. In parallel, prolonged SSC in the delivery room between term healthy infants and their mothers improved infant body temperature and exclusive breastfeeding practice ${ }^{7}$. Interhospital transports of stable newborn infants without respiratory support through the SSC mode were safe and secure for infants and stressless for parents ${ }^{8,9}$. In our hospital, the distance between the birth room and the neonatal intensive care unit (NICU) is approximately 300 meters. Before 2018, all infants requiring intensive care were transported in an incubator. Since the first half of 2018, skin-to-skin transfer in the father's arms has been implemented. A quality assessment of neonatal intrahospital transport modes was carried out in 2019. Then, the cardiorespiratory and thermal stabilities of infants during transfer from the birth room to the NICU, via either incubator or skin-to-skin modes, were observed. Furthermore, the consequences of transfer mode on glycemia, blood gas, the first SSC in the NICU and breastfeeding were also reported.

\section{METHODS}

\section{Study design}


This work was an observational study. All singleton infants born from May to December 2019 in the three-level maternity ward of the University Hospital of Tours (France) who required hospitalization in the closest NICU were eligible. The SQUIRE guidelines were followed for reporting our data ${ }^{10}$.

\section{Ethics}

Written legal consent from guardians for the use of their child's data was obtained. The local ethics committee (2019-082) and local data protection authority (2019-054) approved the protocol.

\section{Transport modalities from the birth room to the NICU}

Newborn infants requiring admission to the NICU were transported after resuscitation either in an incubator in an ambient air atmosphere at $36^{\circ} \mathrm{C}$ or in the father's arms through SSC. The final decision for transfer mode was left to the discretion of the medical team. The medical team included a physician, a resident and a nurse from the NICU. For skin-to-skin transport, the bare-chested father was seated in a mobile chair, and the infant was carried in the kangaroo position using warmed cotton wraps plus plastic bags for infants less than 32 gestational weeks. The infant wore a cotton cap or noninvasive ventilation headgear. The infant's heart rate and oxygen saturation were monitored throughout the procedure regardless of the transfer mode. No infant had intravenous fluid intake during transfer.

\section{Experimental data}

The infant's axillary temperature, heart rate and inspired fraction of oxygen (FiO2) were reported at five timepoints: the time of the medical decision to transfer (T0), at the departure from the birth room (T1), at the arrival in the NICU (T2), at the end of the infant's installation in the NICU incubator (T3) and 30 minutes after T3 (T4). The ventilatory support type, presence of bradycardia, namely, heart rate below 80 beats/minute, and presence of desaturation, namely, oxygen saturation below $85 \%$, during transfer were also reported. Data 
on gestational age, birth weight, sex, delivery type, and 5-minute Apgar score were retrieved along with data on the first glycemia, pH, capnia and SSC in the NICU. Data on parental ages, parental educational levels and breastfeeding were also obtained.

\section{Statistical analysis}

Quantitative variables with normal distributions are expressed as the mean $( \pm$ standard deviation), and Student's t test was used for comparisons. Variables with nonnormal distributions are expressed as medians [range], and Mann-Whitney's nonparametric tests were performed for comparisons. Fisher's exact test was applied for qualitative variables. Two-way ANOVA followed by Bonferroni post hoc tests were performed to analyze the physiologic parameters throughout the procedure. Appropriate regression was used to adjust parameters for gestational age. The significance threshold was strictly $\mathrm{p}<0.05$ for all analyses. Statistical analyses were performed using GraphPad Prism (GraphPad Prism version 5.01 for Windows, GraphPad Software, San Diego, California, USA).

\section{RESULTS}

\section{Patient and parent characteristics}

The data of 111 infants, namely, 54 transported in the incubator and 57 transported with SSC, were available for analysis. Infants transferred to their father's arms had higher gestational ages $(\mathrm{p}=.003)$ (Table 1 and Figure 1). All infants requiring mechanical ventilation were transported in an incubator. Furthermore, infants transferred in incubators were likely to have more severe respiratory distress, as they exhibited higher FiO2 levels at T0 (incubator mode $(\mathrm{n}=54): 32 \%( \pm 21.7)$ vs skin-to-skin mode $(\mathrm{n}=57): 22.7 \%( \pm 4.3), \mathrm{p}=.007)$ (Figure 2$).$ The ages and educational levels of the mothers in the two experimental groups were similar $(\mathrm{p}=$ .36 and $p=.68$, respectively $)$, as were those of the fathers $(p=.34$ and $p=.2$, respectively).

\section{Skin-to-skin transfer mode safety}


The total durations of transport (i.e., from T0 to T3) were similar between the two experimental groups (incubator mode $(n=34)$ : 27.5 minutes [14,68] vs skin-to-skin mode $\mathrm{n}=43$ ): 28 minutes $[17,95], \mathrm{p}=.81)$. No bradycardia occurred, and the desaturation frequency in both groups was relatively low (Table 1). The mean heart rate and the mean $\mathrm{FiO} 2$ remained stable from T0 to T3 in the skin-to-skin group (mean heart rate decrease: 3 beats/minute $( \pm 15)$ ) (Figure 2). The first glycemia measurements in the NICU were similar regardless of the transfer mode, even after adjustment for gestational age $(\mathrm{p}=.43)$ (Table 1). Regarding thermal stability, a significant temperature decrease was observed during installation in the NICU room for infants transferred via skin-to-skin mode (median temperature variation from T2 to T3: incubator mode $(n=44)=0{ }^{\circ} \mathrm{C}[-1,+0.7]$ vs skin-to-skin mode $(n=51)=-0.2^{\circ} \mathrm{C}[-1$, $+0.4], \mathrm{p}<.001$ ) (Figure 2). This temperature decrease was still significant after adjustment for gestational age $(\mathrm{p}=.006)$. No recovery was observed 30 minutes later. Although the mean temperatures were similar at T0 (incubator mode $(n=51)=36.67^{\circ} \mathrm{C}( \pm 0.56)$ vs skin-to-skin mode $\left.(n=55)=36.63^{\circ} \mathrm{C}( \pm 0.7), \mathrm{p}=.73\right)$, the mean temperature at $\mathrm{T} 4$ was significantly lower in infants transported via skin-to-skin mode (incubator mode $(n=45)=36.61^{\circ} \mathrm{C}( \pm 0.62)$ vs skinto-skin mode $\left.(\mathrm{n}=52)=36.26^{\circ} \mathrm{C}( \pm 0.63), \mathrm{p}=.007\right)$ (Figure 2$)$. This effect on axillary temperature at T4 remained significant after adjustment for gestational age $(\mathrm{p}<.001)$.

\section{Impact of skin-to-skin transfer on NICU course}

The delay in the first skin-to-skin contact performed in the NICU was significantly shorter in the skin-to-skin group $(\mathrm{p}=.001)$ (Table 1). This effect persisted after adjustment for gestational age $(\beta=-17.8, \mathrm{p}=.008)$. More women started to breastfeed their infants in the skinto-skin transfer group and succeeded in maintaining breastfeeding at discharge, although the threshold of significance was not reached $(\mathrm{p}=.14$ and $\mathrm{p}=.09$, respectively) (Table 1$)$. This trend persisted after adjustment for gestational age (aOR 2.4 [0.95-6.11], $\mathrm{p}=.06$ and aOR 1.99 [0.93-4.24], $\mathrm{p}=.07$, respectively). 


\section{DISCUSSION}

Skin-to-skin transfers from the birth room to the neonatal unit were feasible for newborn infants spontaneously breathing with or without noninvasive ventilation. Cardiorespiratory function and glycemia were not compromised during this procedure. Furthermore, earlier SSC in the neonatal unit and a trend of an increase in breastfeeding practice were observed in the skin-to-skin transfer group. However, concerns emerged about thermal stability. The transfer from the father's arm to the incubator in the NICU room was critical for thermal loss and needs to be improved.

The temperature value at admission to the NICU has become a critical parameter for very preterm infant management. Lower mortality rates and a lower prevalence of severe morbidity were observed in very preterm infants exhibiting temperatures ranging from $36.5^{\circ} \mathrm{C}$ to $37.2^{\circ} \mathrm{C}$ ${ }^{11}$. Furthermore, Wilson et al. reported that a temperature less than $35.5^{\circ} \mathrm{C}$ was associated with an increase in very preterm infant mortality ${ }^{12}$. Thus, the heat loss during installation in the NICU linked to the skin-to-skin mode raised important concerns. Transfer between an incubator and SSC was previously associated with a decrease in skin temperature of very preterm infants, with a progressive recovery from 30 to 60 minutes ${ }^{5,6}$. Interestingly, the transfer back to the incubator induced a deeper and more prolonged decrease in skin temperature ${ }^{5}$. In parallel, lower body temperature during the first hour of life was recently observed in very preterm infants receiving SSC immediately after birth rather than being placed into an incubator ${ }^{13}$. This finding led to changes focusing on thermal conservation during installation in the NICU. A plastic wrap and cap had a preventative effect on hypothermia during the poststabilization period in infants with a gestational age below 34 weeks ${ }^{14,15}$. Therefore, the systematic use of plastic caps and bags was implemented in the unit for the transfer from SSC to the incubator. This procedure is currently under assessment. 
Although the continuation of skin-to-skin transfer regarding thermal safety raised concerns, encouraging results in the SSC group regarding early SSC and initiation of breastfeeding in the NICU suggest that there are benefits to skin-to-skin transfers. These results supported previous studies reporting that early SSC with the mother promoted breastfeeding in late preterm and term infants $7,16,17$. However, in a pilot study, Linner et al reported similar proportions of breastfeeding among dyads experiencing or not experiencing SSC in the delivery room ${ }^{13}$. In parallel, early implementation and regular practice of SSC in the NICU demonstrated undoubtedly beneficial effects for preterm infants ${ }^{1}$.

Skin-to-skin transfers were exclusively performed with fathers due to the need for rapid transfer to the NICU. The infant-father dyad went to meet the mother in the delivery room. Maastrup et al suggested that thermal neutrality was better during SSC with mothers than with fathers ${ }^{5}$. In the future, skin-to-skin transfer with the mother should be considered.

This observational study revealed that very preterm infants and infants requiring mechanical ventilation were preferentially transported in an incubator. However, this population could be an interesting target for skin-to-skin transfer. This topic has stimulated great interest, as two randomized controlled trials focusing on the assessment of early SSC with mothers during the extrauterine life adaptation of very preterm infants are ongoing ${ }^{18,19}$.

\section{Limitations}

This study aimed to assess the safety and quality of transfer practices in our unit. Due to its observational design, large differences in population profiles and missing data, though these events were few, weakened the interpretation of the results. However, this study allowed us to point out the pitfalls linked to SSC transfer and to focus on the required improvements to implement this practice for more vulnerable patients. From this pilot study, a randomized controlled and multicenter trial focusing on infants with a gestational age strictly under 34 
weeks was designed to compare SSC and incubator transfers, and the trial is under evaluation for governmental funding in the nursing care category.

\section{CONCLUSION}

Skin-to-skin transfer from the birth room to the NICU is likely to be promising despite unexpected heat loss during installation in the NICU. Further studies are needed to assess the impact of skin-to-skin transport on very preterm infants and infants requiring mechanical ventilation.

\section{REFERENCES}

1. Feldman R, Eidelman AI, Sirota L, Weller A. Comparison of skin-to-skin (kangaroo) and traditional care: parenting outcomes and preterm infant development. Pediatrics. 2002;110(1 Pt 1):16-26. doi:10.1542/peds.110.1.16

2. Feldman R, Rosenthal Z, Eidelman AI. Maternal-Preterm Skin-to-Skin Contact Enhances Child Physiologic Organization and Cognitive Control Across the First 10 Years of Life. Biol Psychiatry. 2014;75(1):56-64. doi:10.1016/j.biopsych.2013.08.012

3. Lorenz L, Dawson JA, Jones H, et al. Skin-to-skin care in preterm infants receiving respiratory support does not lead to physiological instability. Arch Dis Child - Fetal Neonatal Ed. 2017;102(4):F339-F344. doi:10.1136/archdischild-2016-311752

4. Blomqvist YT, Karlsson V, Dawit F, Sindelar R, Ågren J. Physiological Stability in Very Preterm Infants During Skin-to-Skin Contact as Assessed by Near-Infrared Spectroscopy. Adv Neonatal Care. 2020;20(6):495-498. doi:10.1097/ANC.0000000000000764

5. Maastrup R, Greisen G. Extremely preterm infants tolerate skin-to-skin contact during the first weeks of life: Skin-to-skin contact in extremely preterm infants. Acta Paediatr. 2010;99(8):1145-1149. doi:10.1111/j.1651-2227.2010.01806.x

6. Karlsson V, Heinemann A-B, Sjörs G, Nykvist KH, Ågren J. Early Skin-to-Skin Care in Extremely Preterm Infants: Thermal Balance and Care Environment. J Pediatr. 2012;161(3):422-426. doi:10.1016/j.jpeds.2012.02.034

7. Moore ER, Bergman N, Anderson GC, Medley N. Early skin-to-skin contact for mothers and their healthy newborn infants. Cochrane Pregnancy and Childbirth Group, ed. Cochrane Database Syst Rev. November 2016. doi:10.1002/14651858.CD003519.pub4

8. Sontheimer D, Fischer CB, Buch KE. Kangaroo Transport Instead of Incubator Transport. PEDIATRICS. 2004;113(4):920-923. doi:10.1542/peds.113.4.920

9. Hennequin Y, Grevesse L, Gylbert D, Albertyn V, Hermans S, Van Overmeire B. Skinto-skin back transfers provide a feasible, safe and low-stress alternative to conventional neonatal transport. Acta Paediatr. 2018;107(1):163-164. doi:10.1111/apa.14071 
10. Ogrinc G, Davies L, Goodman D, Batalden P, Davidoff F, Stevens D. SQUIRE 2.0 ( Standards for QUality Improvement Reporting Excellence): revised publication guidelines from a detailed consensus process: Table 1. BMJ Qual Saf. 2016;25(12):986992. doi:10.1136/bmjqs-2015-004411

11. Lyu Y, Shah PS, Ye XY, et al. Association Between Admission Temperature and Mortality and Major Morbidity in Preterm Infants Born at Fewer Than 33 Weeks' Gestation. JAMA Pediatr. 2015;169(4):e150277. doi:10.1001/jamapediatrics.2015.0277

12. Wilson E, Maier RF, Norman M, et al. Admission Hypothermia in Very Preterm Infants and Neonatal Mortality and Morbidity. $J$ Pediatr. 2016;175:61-67.e4. doi:10.1016/j.jpeds.2016.04.016

13. Linnér A, Klemming S, Sundberg B, et al. Immediate skin-to-skin contact is feasible for very preterm infants but thermal control remains a challenge. Acta Paediatr. 2020;109(4):697-704. doi:10.1111/apa.15062

14. McCall EM, Alderdice F, Halliday HL, Vohra S, Johnston L. Interventions to prevent hypothermia at birth in preterm and/or low birth weight infants. Cochrane Neonatal Group, ed. Cochrane Database Syst Rev. February 2018. doi:10.1002/14651858.CD004210.pub5

15. Li S, Guo P, Zou Q, He F, Xu F, Tan L. Efficacy and Safety of Plastic Wrap for Prevention of Hypothermia after Birth and during NICU in Preterm Infants: A Systematic Review and Meta-Analysis. Baud O, ed. PLOS ONE. 2016;11(6):e0156960. doi:10.1371/journal.pone.0156960

16. Aghdas K, Talat K, Sepideh B. Effect of immediate and continuous mother-infant skinto-skin contact on breastfeeding self-efficacy of primiparous women: A randomised control trial. Women Birth. 2014;27(1):37-40. doi:10.1016/j.wombi.2013.09.004

17. Marín Gabriel M, Llana Martín I, López Escobar A, Fernández Villalba E, Romero Blanco I, Touza Pol P. Randomized controlled trial of early skin-to-skin contact: effects on the mother and the newborn: Skin-to-skin contact: effects on the mother and the newborn. Acta Paediatr. 2010;99(11):1630-1634. doi:10.1111/j.16512227.2009.01597.x

18. Kristoffersen L, Støen R, Rygh H, et al. Early skin-to-skin contact or incubator for very preterm infants: study protocol for a randomized controlled trial. Trials. 2016;17(1):593. doi:10.1186/s13063-016-1730-5

19. Linnér A, Westrup B, Lode-Kolz K, et al. Immediate parent-infant skin-to-skin study (IPISTOSS): study protocol of a randomised controlled trial on very preterm infants cared for in skin-to-skin contact immediately after birth and potential physiological, epigenetic, psychological and neurodevelopmental consequences. BMJ Open. 2020;10(7):e038938. doi:10.1136/bmjopen-2020-038938 


\section{TABLE AND FIGURE CAPTIONS}

\section{Table 1: Patient characteristics}

Figure 1: Transport mode practices according to infants' gestational age. Gray bars correspond to infants transported in an incubator. White bars correspond to infants transferred via the skin-to-skin contact mode.

Figure 2: Evolution of physiological parameters from the birth room to the NICU according to transport mode. The inspired fraction of oxygen (FiO2) (A), heart rate (B) and axillary temperature $(\mathrm{C})$ are reported on graphs according to the five steps of the transfer. These 5 steps included i) T0: medical decision to transfer, ii) T1: departure from the birth room, iii) T2: arrival in the NICU, iv) T3: end of the infant's installation in the NICU incubator, v) T4: 30 minutes after T3. Black circles represent infants transported in the incubator. Empty circles represent infants transported via the skin-to-skin contact mode. The results are expressed as the mean \pm standard deviation. Statistical analysis: Two-way ANOVA with Bonferroni post hoc test, ${ }^{*} \mathrm{p}<.05, * * \mathrm{p}<.01, * * * \mathrm{p}<.001$. 
Table 1: Patient characteristics

\begin{tabular}{|c|c|c|c|}
\hline & $\begin{array}{l}\text { Incubator transfer } \\
\qquad(\mathrm{n}=54)\end{array}$ & $\begin{array}{l}\text { Skin-to-skin } \\
\text { transfer }(n=57)\end{array}$ & $\mathrm{p}$ \\
\hline $\begin{array}{l}\text { Gestational age (weeks of gestation) } \\
\text { median [range] }\end{array}$ & $32[24,41]$ & $36[27,41]$ & $.003^{\mathrm{a}}$ \\
\hline $\begin{array}{l}\text { Birth weight (grams) } \\
\text { median [range] }\end{array}$ & $1612[650,3865]$ & $2590[890,4630]$ & $.004^{\mathrm{a}}$ \\
\hline $\begin{array}{l}\text { Birth weight percentile } \\
\text { median [range] }\end{array}$ & $41[0,98]$ & $37[0,100]$ & $.9^{\mathrm{a}}$ \\
\hline Small for gestational age, $\mathrm{n}(\%)$ & $11(20.4)$ & $7(12.3)$ & $.23^{\mathrm{b}}$ \\
\hline Male infants, $\mathrm{n}(\%)$ & $37(68.5)$ & $33(57.9)$ & $.25^{\mathrm{b}}$ \\
\hline C-section, n (\%) & $38(70.4)$ & $32(56.1)$ & $.12^{\mathrm{b}}$ \\
\hline $\begin{array}{l}\text { 5-minute Apgar score, } \\
\text { median [range], (missing values) }\end{array}$ & $\begin{array}{c}8[1,10] \\
(1)\end{array}$ & $\begin{array}{c}9[4,10] \\
(4)\end{array}$ & $.1^{\mathrm{a}}$ \\
\hline $\begin{array}{l}\text { Mechanical ventilation for transfer, } \\
\mathrm{n}(\%)\end{array}$ & $17(31)$ & $0(0)$ & $<.001^{\mathrm{b}}$ \\
\hline $\begin{array}{l}\text { Non-invasive ventilation for transfer, } \\
\mathrm{n}(\%)\end{array}$ & $29(54)$ & $42(74)$ &. $\mathbf{0 3}^{\mathrm{b}}$ \\
\hline $\begin{array}{l}\text { Infants exhibiting bradycardia during } \\
\text { transfer, } \mathrm{n}(\%)\end{array}$ & $0(0)$ & $0(0)$ & $1^{\mathrm{b}}$ \\
\hline $\begin{array}{l}\text { Infants exhibiting desaturation } \\
\text { during transfer, } \mathrm{n}(\%)\end{array}$ & $3(5.5)$ & $3(5)$ & $1^{\mathrm{b}}$ \\
\hline $\begin{array}{l}\text { First glycemia measurement in the } \\
\text { unit }(\mathrm{g} / \mathrm{L}), \text { median [range] }\end{array}$ & $0.56[0.03,1.9]$ & $0.62[0.03,1.3]$ & $.52^{\mathrm{a}}$ \\
\hline $\begin{array}{l}\text { First } \mathrm{pH} \text { in the unit } \\
\text { mean }( \pm \mathrm{SD}), \text { (missing values) }\end{array}$ & $\begin{array}{c}7.29( \pm 0.08) \\
(6)\end{array}$ & $\begin{array}{c}7.29( \pm 0.07) \\
(5)\end{array}$ & $.83^{\mathrm{c}}$ \\
\hline $\begin{array}{l}\text { First } \mathrm{PCO}_{2} \text { in the unit }(\mathrm{mmHg}) \\
\text { mean }( \pm \mathrm{SD}),(\text { missing values })\end{array}$ & $\begin{array}{c}49.1( \pm 11.8) \\
(5)\end{array}$ & $\begin{array}{c}50.3( \pm 10.6) \\
(5)\end{array}$ & $.58^{\mathrm{c}}$ \\
\hline $\begin{array}{l}\text { First skin-to-skin contact in the unit } \\
\text { (hours from birth), median [range] } \\
\text { (missing values) }\end{array}$ & $\begin{array}{c}22[2,165] \\
\quad(8)\end{array}$ & $\begin{array}{c}11[1,136] \\
(4)\end{array}$ & $.001^{\mathrm{a}}$ \\
\hline Breastfeeding initiation, $\mathrm{n}(\%)$ & $37(68.5)$ & $46(81)$ & $.14^{\mathrm{b}}$ \\
\hline Breastfeeding at discharge, $\mathrm{n}(\%)$ & $24(44)$ & $35(61)$ & $.09^{\mathrm{b}}$ \\
\hline
\end{tabular}

SD: Standard Deviation.

Statistical analyses: ${ }^{\mathrm{a}}$ Mann-Whitney's nonparametric test, ${ }^{\mathrm{b}}$ Fisher's exact test, ${ }^{\mathrm{c}}$ Student's $\mathrm{t}$ test for independent samples.

Bold values indicate a significant difference, i.e., $\mathrm{p}<0.05$. 


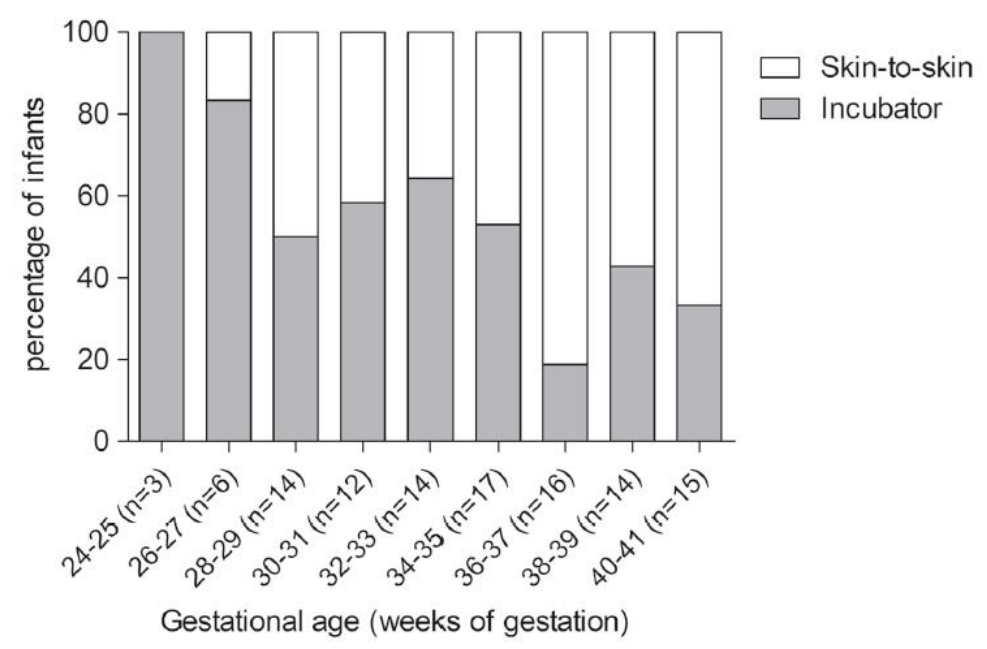

Clenet et al., Figure 1 
A

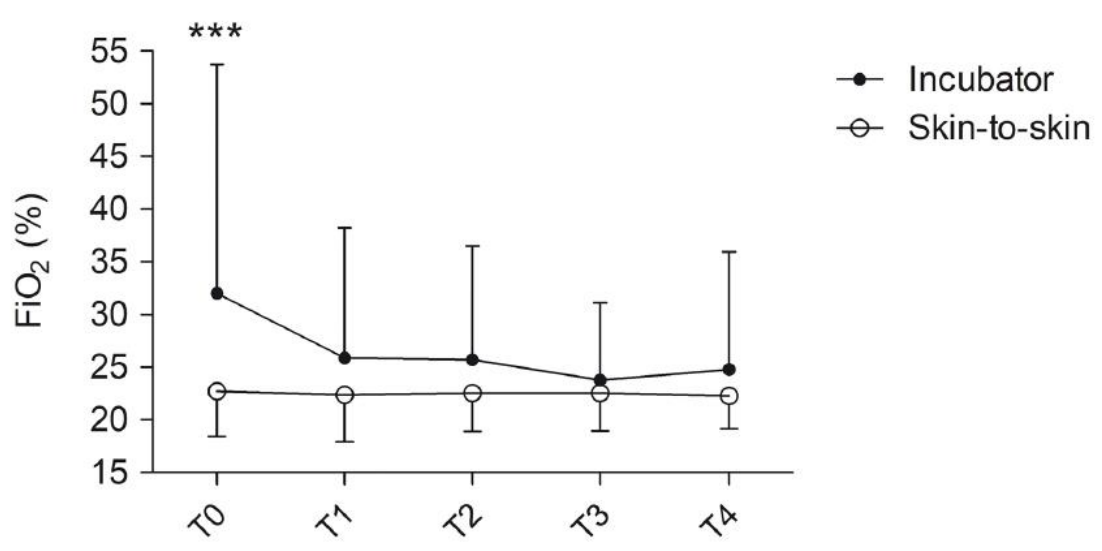

B

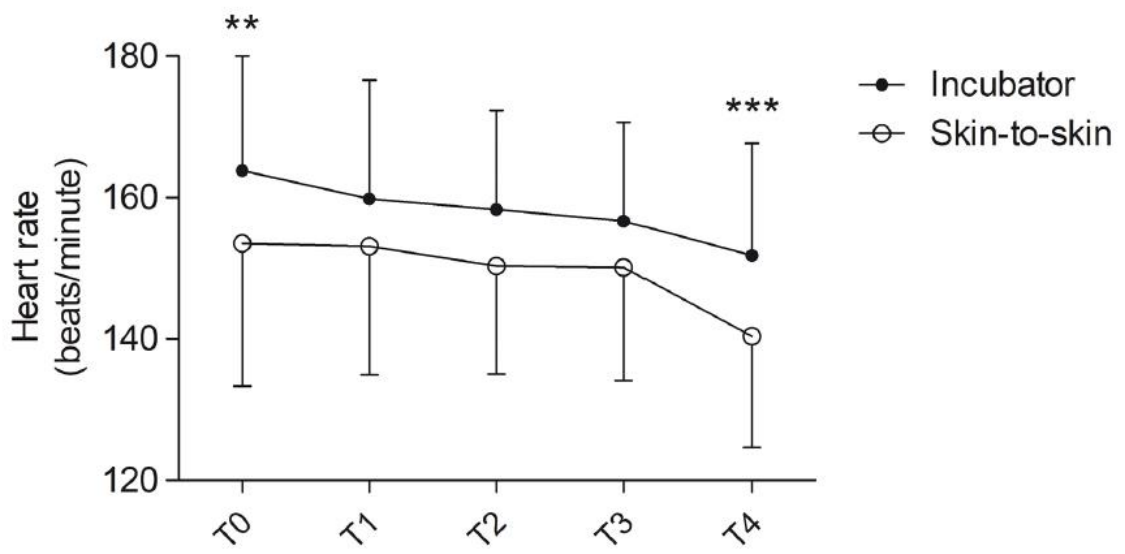

C

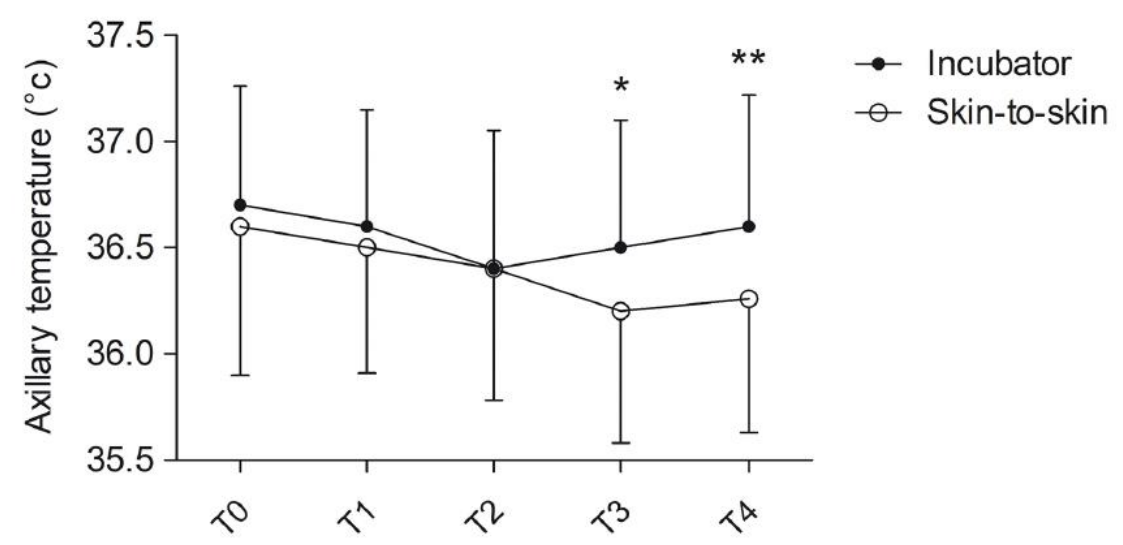

Clenet et al., Figure 2 
Figures

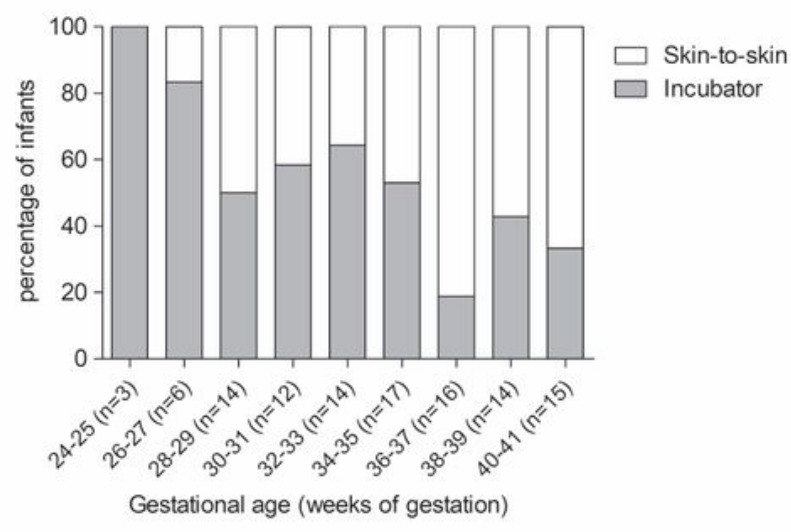

Clenet et al., Figure 1

\section{Figure 1}

Transport mode practices according to infants' gestational age. Gray bars correspond to infants transported in an incubator. White bars correspond to infants transferred via the skin-to-skin contact mode. 
A

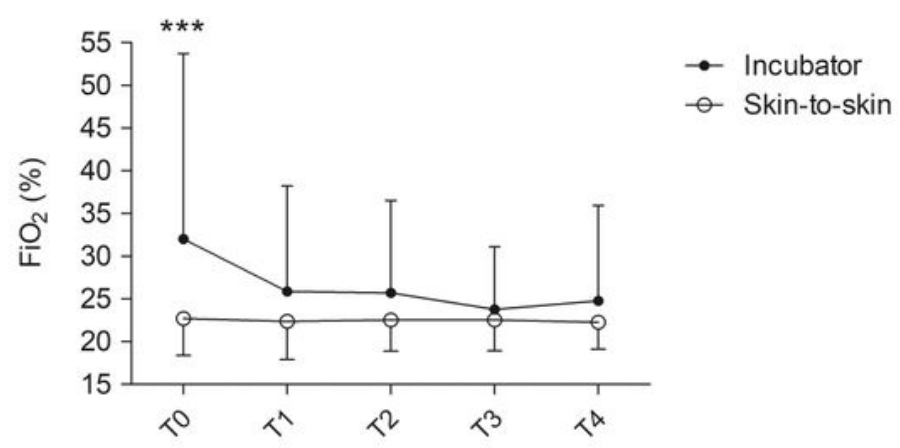

B

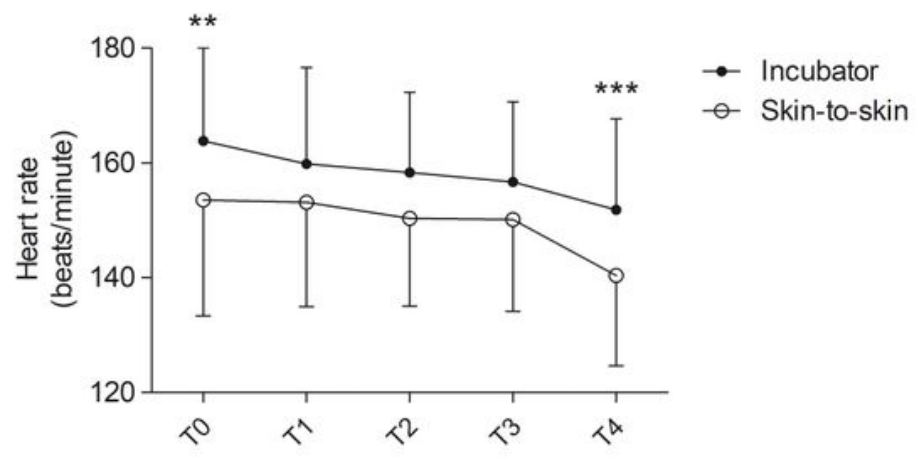

C

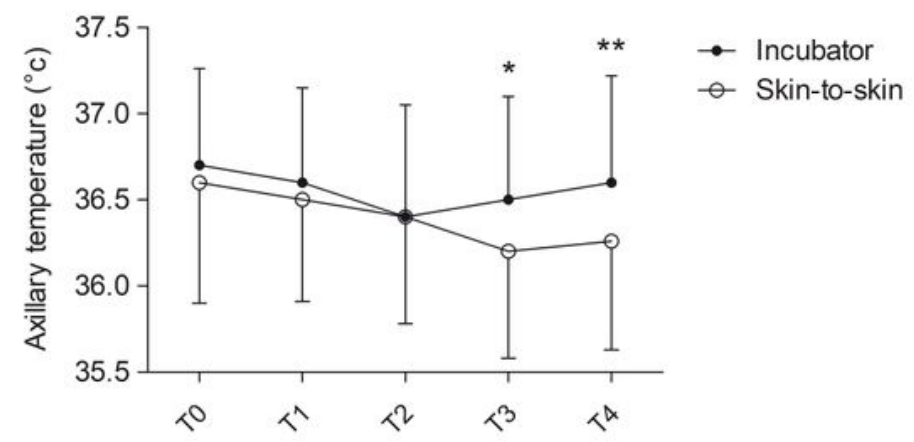

Clenet et al., Figure 2

\section{Figure 2}

Evolution of physiological parameters from the birth room to the NICU according to transport mode. The inspired fraction of oxygen ( $\mathrm{FiO2})(\mathrm{A})$, heart rate $(\mathrm{B})$ and axillary temperature $(\mathrm{C})$ are reported on graphs according to the five steps of the transfer. These 5 steps included i) T0: medical decision to transfer, ii) T1: departure from the birth room, iii) T2: arrival in the NICU, iv) T3: end of the infant's installation in the NICU incubator, v) T4: 30 minutes after T3. Black circles represent infants transported in the incubator. 
Empty circles represent infants transported via the skin-to-skin contact mode. The results are expressed as the mean \pm standard deviation. Statistical analysis: Two-way ANOVA with Bonferroni post hoc test, ${ }^{*} \mathrm{p}<.05,{ }^{* *} \mathrm{p}<.01,{ }^{* \star *} \mathrm{p}<.001$. 